\title{
Corrective Feedback: A Bridge between Cognitive Interactionist and Social Interactionist Perspectives
}

\author{
Naif Althobaiti* \\ Department of Foreign Languages, Taif University, Taif, Saudi Arabia \\ *Corresponding author: althobaiti@tu.edu.sa
}

Received September 30, 2014; Revised October 20, 2014; Accepted October 23, 2014

\begin{abstract}
This presentation tries to explain oral corrective feedback (CF) as provided through conversational interaction. In this presentation, CF, as provided through the interaction, is viewed from two perspectives: the cognitive interactionist and the social interactionist. Although, both of these two perspectives value interaction, they explicate the provision of CF through interaction differently. The cognitive interactionists explain the provision of CF through, but not limited to, Interaction Hypothesis, Noticing Hypothesis, and Output Hypothesis. The social interactionists emphasize the roles of teachers and learners within the process of corrective feedback. They also emphasize the context in which they work and the specific pedagogic activity in which they are involved (Ellis, 2008; 2010). This presentation is hoped to contribute a better understanding of EFL learning facilitated through the provision of $\mathrm{CF}$. In addition, it provides some recommendations for future researchers, language educators, and EFL teachers.
\end{abstract}

Keywords: corrective feedback, interaction, cognitive interactionist, social interactionist, EFL context

Cite This Article: Naif Althobaiti, "Corrective Feedback: A Bridge between Cognitive Interactionist and Social Interactionist Perspectives.” American Journal of Educational Research, vol. 2, no. 10 (2014): 950-954. doi: 10.12691/education-2-10-15.

\section{Introduction}

CF has been described as a complex phenomenon which requires a great deal of attention. Its complexity can be seen in the way the popular grammar books suggest that teachers utilize it, the large number of studies exploring its facilitative role in different contexts, and the inconclusiveness of the studies' results [35]. Thus, to fully understand $\mathrm{CF}$, a multiple perspectives approach is required [9]. Therefore, this paper discusses CF from the cognitive perspective as well as the socio-cultural perspective. Specifically, it addresses oral CF. Written corrective feedback is not included in the scope of this presentation because there is limited evidence for it and it is treated as a separate phenomenon to oral CF in the literature [3].

In the broadest sense, cognitive-interactionism is concerned with internal factors of human interaction, while socioculturalism is concerned with the external factors of human interaction [19,21-34]. Both perspectives address and value the utility of corrective feedback obtained through conversational (i.e., teacher-students) interaction, which in turn is claimed to lead to language learning and development [11]. This paper, therefore, is divided into four sections. The first section sheds light on the interactionist perspective and the term 'interaction.' The second section discusses the cognitive interactionist perspective. The third section discusses the sociocultural perspective. The last section suggests a possible bridge between these two perspectives.

Most Second Language Acquisition (SLA) theories emphasize the importance of input and the linguistic environment to provide both positive and negative evidences (See Figure 1), which are critical features for the acquisition of the first language (LI) and subsequently acquired language(s) [4,18,34]. Positive evidence provides information about the acceptable usage of language; meanwhile, negative evidence provides information about the unacceptable usage of language [12,26]. Negative evidence is provided either before the learner tries to produce an utterance or in reaction to his/her erroneous utterance.

To elaborate, Long [23] considered negative evidence and positive evidence as environmental information learners receive in response to their language utterances. Positive evidence provides the learners with the grammatical and acceptable use of the target language (TL) via modeling. Negative evidence, however, is information about the unacceptable usage of the TL that is either explicitly or implicitly provided to the learners.

Furthermore, Long [24] offered the following framework, integrating positive and negative evidence with regard to the linguistic environment, that is, input:

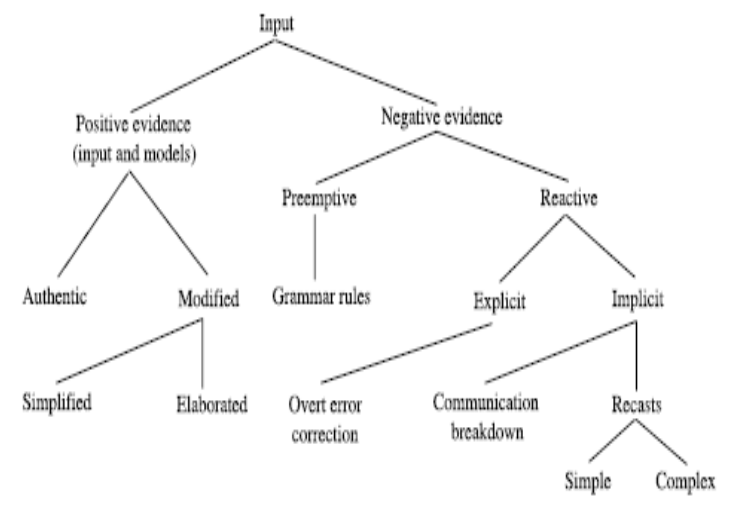

Figure 1. Types of input for second language acquisition (Adapted from Long \& Robinson 1998: 15-4) 
The terms negative evidence, negative feedback, and corrective feedback are often used interchangeably in the fields of language teaching, SLA, and psychology [13]. The three terms refer to "the input that tells learners what is not possible or not grammatical in the target language” [[36], p. 296]. Accordingly, corrective feedback refers to negative evidence that tells the learner that the use of the target language is unacceptable or incorrect.

In short, negative evidence is claimed to promote acquisition [21]. The role of corrective feedback as a response or a reaction to learners' erroneous utterances is considered to be facilitative. This facilitative role of corrective feedback is attained by means of conversational (teacher-students) interaction [12,23].

The conversational interaction is argued to provide learners with an opportunity of acquisition. It creates a rich environment where learners are exposed to comprehensible input, output opportunities, and interactional feedback. Interaction, the term from which the Interactionist perspective derives its name, stems from the seminal work of Hatch in the 1970s and early 1980s. Hatch's work indicated that conversation was commonly viewed as a practice site for grammatical structure learned in a formal classroom [8]. Therefore, interaction, as the means through which corrective feedback (i.e., negative evidence) is provided, is viewed from two perspectives: cognitive and sociocultural.

The term interaction, as it is used in this presentation, requires clarification. Interaction refers to dyadic or triadic verbally negotiated interactions which are conducted either between, but not limited to, an ESL/EFL teacher and a learner, or between two or more EFL/ESL learners [23]. For example:

Teacher: Why should parents be honest?

Learner: To learn their children (Lexical error)

Teacher: To teach their children (Recast)

Student: Yes, to teach.

In this example of conversational interaction, the teacher provides the learner with an explicit correction that reveals the verb selection error [2]. Having defined $\mathrm{CF}$ and interaction, the following section discusses the cognitive interactionist perspective.

\section{Cognitive Interactionist Approach}

The cognitive interactionist approach views language learning as an individual cognitive effort. The possibility of learning occurrence is dependent on learner's cognitive capacity as a result of input, interaction, notching, and output. These are the main theoretical constituents of the cognitive approach [35]. These theoretical constituents are attributed to linguistics, psychological, and pedagogical perspectives of learning [27]. Two more constituents had been attached to this approach: focus on form and counterbalance hypothesis. They are related to the previous mentioned constituents with more emphasis on noticing.

Therefore, this section deals with theoretical constituents through which learning is explicated and thus $\mathrm{CF}$ is viewed as contributing to this learning. The concepts are comprehensible input, interactionist hypothesis, comprehensible output, noticing, focus on form, and counterbalance hypothesis. The section ends with an attempt to connect CF to learning in light of these concepts.

In its broadest sense, the proponents of the cognitiveinteractionist approach view the language learning, especially second/foreign language learning, as constituting the knowledge of that language in the learner's cognition. As time passes, this knowledge is believed to be utilized automatically for speaking and understanding [26,35]. This view is represented in Krashen's claim that comprehensible input to which learners are exposed is all learners need for learning. The comprehensible input is slightly beyond the learner's current grammatical knowledge and capability [12,35]. Eventually, the comprehensible input will be integrated in learners' interlanguage grammar which, in turn, enables them to produce the target language [13,23]. However, Krashen's claim is dependent on unidirectional instruction which is teacher dominated. This claim had been the motive for many subsequent researches and has led to the emergence of the interaction hypothesis.

The interaction hypothesis states that comprehensible input is necessary but insufficient for acquisition to take place [23]. Therefore, Long proposed that there must be verbal interactions which should include modifications either via negotiation of form or negotiation of meaning. By providing learners with an opportunity to interact, they are more likely to pay attention to the input provided. Long's interaction hypothesis led to the emergence of the output hypothesis.

The output hypothesis was proposed by Swain [37] to complement the input hypothesis. According to Swain, as the interaction provides learners with rich opportunities for input, it helps them with comprehensible output as well. She added that when learners are pushed to participate in conversations (i.e., to produce output), they are involved in both semantic and syntactic processing [38]. Thus, input is not enough even if it is comprehensible; there must be interaction and output opportunities to help learning take place.

Although Long and Swain proposed interaction and output hypothesis to complement input, researchers such as Schmidt claimed the learning process is incomplete unless it includes noticing. Thus, Schmidt proposed the noticing hypothesis in an effort to make students notice the difference between the produced interlanguage forms and the target language forms.

Later on, researchers conducted many investigations and came up with new pedagogical proposals to bridge the gaps between the aforementioned constituents such as Focus on Form (FoF). It was proposed by Long [22] and aimed to draw learners' attention to specific linguistic elements explicitly even if the focus is on meaning. By virtue of integrating both the interaction hypothesis and the noticing hypothesis, FoF is considered to be an effective approach to L2 instruction [21].

In the same juncture of interaction and enhancing attention, the counterbalance hypothesis was originated in the work of Leyster and Mori [25] who asserted that teachers are recommended to conduct a counter pedagogical intervention to their mostly used one. In other words, if they address accuracy in their classes, they need to switch to addressing fluency. If they focus on forms, they are advised to focus on meaning. According to Lyster and Mori, such a switch should enhance students' awareness 
of the target forms and, in turn, encourage their uptake and output as well.

\subsection{Connection to CF}

The cognitive approach as an umbrella term for the previously mentioned constituents reveals them to be discrete but complementary. They are independent theories but they can complement each other in explicating the occurrence of language learning.

Cognitive interactionists see CF as facilitative and contributing to language learning either implicitly or explicitly. The cognitive theories related to CF are interaction hypothesis, output hypothesis, noticing hypothesis, FOF, and counter balance hypothesis. CF can function on the language development because it occurs during communicative activities which have the potential to involve students in interactions, paying attention to the meaning and the form of the target item, forcing them to produce the target form. Then, when students make errors, they receive corrective feedback to enhance their awareness of the meaning of the target form in its particular context. Therefore, such feedback is claimed to facilitate the uptake and the incorporation of the correct TL forms.

This section should provide an attempt to connect CF to language learning through the cognitive interactionist perspective lens. The following section discusses the social interactionist perspective and the lens through which CF is looked at as facilitating language learning.

\section{Social Interactionist Perspective}

Social interaction perspective draws heavily on the works of Lev Semenovitch Vygotsky [39], the Russian developmental psychologist, who developed it as an alternative to individualistic information processing theories of cognition and learning. It claims that learning happens through interaction with a more capable peer, rather than a result of it [2].

Social interactionists have considered expanding this perspective to language over the last few decades [26]. This is apparent in numerous researches, including the works of Lantolf [20] and Lantolf and Thorne [19]. However, such a perspective has not received the attention it deserves either theoretically or practically [10]. Yet, this argument remains valid up to the present day [3]. Researchers are not tempted to cross cognitive boundaries in their studies. Thus, they neglect the social perspective in one way or another, either because of a lack of theoretical grounding or empirical evidences. This scarcity of evidence and research is evident when focusing on CF [3].

This led some researchers to claim that both cognitive and social perspectives of learning are almost interrelated and similar; they just utilize different terms to explicate the learning process [26].

In spite of the fact that social interactionism has not received enough empirical evidence, a few seminal works, such as Aljaafreh and Lantolf [1] and Nassaji [28,29], provide support for it, although CF was not the main focus of these two studies. Russell [31] in her review and Ellis [9] in his proposed framework for CF both indicated a big gap in researching $\mathrm{CF}$ from a social perspective.
Therefore, this paper is hoped to give impetus for future efforts by drawing a theoretical outline for the social interactionist perspective when investigating oral CF. The following sections touch briefly on the main constructs of the social interactionist perspective as it relates to oral CF. The constructs are mediation, regulation and internalization, and the zone of proximal development.

\subsection{Main Constructs Related to CF}

\subsubsection{Mediation}

Mediation refers to the process of mediating cognitive activities by participating in social interactions (i.e., conversational interactions) [20]. Lantolf indicated that mediation in language learning can take three forms: mediation by others in social interactions, mediation by the self, and mediation by artifacts [20]. Mostly, teacher's verbal directions and interactions with students play a meditational role. Medication, in one way or another, could lead to regulation.

\subsubsection{Regulation and Internalisation}

Regulation is a gradual process by which an individual moves toward a higher cognitive ability, with the assistance of an expert or a knowledgeable other or peer to work eventually without that assistance [16]. The expert's job in the regulation process is to demonstrate new concepts to the learner in order to be imitated. After this, it is claimed the learner achieves autonomy in performing the task, by moving gradually from other-regulation to self-regulation [20]. The learner's movement from otherregulation to self-regulation indicates that they have appropriated the experts' instructions and they can learn the new concepts and skills, organize their thoughts, and control their actions [1]. This movement is also called internalization and explains the shift by the learner from socially-mediated activity to internal-mediated activity [20].

Within regulation, CF has been emphasized as the incorporation of the expert's (teacher's) correction and assistance in the subsequent production. Thus, when learners commit errors, they receive CF from the teacher and uptake that correction in a way that prevents similar errors.

\subsubsection{Zone of Proximal Development (ZPD)}

The concept of the ZPD refers to the gap between what the learner can achieve without the assistance of the more capable peer through the social interaction [6]. Moreover, Mitchell and Myles described the concept of the ZPD as the most suitable condition for learning and "links processes of instruction, organized learning and 'naturalistic' development or acquisition in a single site” (p. 200).

\subsection{Connection to $\mathbf{C F}$}

The amount of teacher assistance (i.e., CF) determines whether or not ZPD is constructed and self-regulation is achieved. This, in turn, determines the learners' internalization of the correction. In other words, once selfregulation is reached, students' are more likely to be able to internalize the correct TL forms. CF, as a cause for regulation to be reached, is claimed to help students' internalization. Therefore, students are most probably 
ready to benefit from CF if they receive fair amount of teacher's regulation within their ZPD. In this way, teachers should be aware of students' different corrective needs and tailor their assistance accordingly. After that, teacher's assistance can be removed/reduced gradually until students' self-regulation is achieved. This has been illuminated in the regulatory scale of Aljaafreh and Lantolf [1], which shows the tutor assistance for the learner; the scale moves from implicit to explicit assistance. This occurs happens gradually until the learner achieves self-regulation.

To sum up, this section has presented the main key constructs of the social interactionist perspective to second language learning in general and corrective feedback in particular. It started by investigating the Vygotskian view of language learning and language. Then, it moved to mediation. After that, it investigated some constructs with regards to corrective feedback, such as regulation, internalization, ZPD, and how these constructs are related and connected to CF. Finally, the section ended by showing the regulatory scale of how learners' independence ranges from being other-regulated to fully self-regulated. The following section shows the intersections of the cognitive interactionist and the social interactionist perspectives. It also shows the author's suggestions to bridge these two perspectives and discusses the role of CF as the driving force for this bridging.

\section{The Bridging Attempt}

As discussed earlier, CF has been dealt with as a complex phenomenon that warrants attention. The way it is provided, when it is provided, and who provides it have been the subject of many studies [9]. The case is further complicated when dealing with various contexts and the efficacy of different CF types [35,39]. Thus, many researchers have called for a multidimensional perspective by which to view CF in order to best facilitate its benefits to language learning [9].

This paper, therefore, has been an attempt to compromise the two perspectives of the cognitive interactionist and the social interactionist. There should be no controversies when navigating through these two perspectives. Learning (i.e., uptake or correction incorporation in a subsequent production or even selfregulation) is the ultimate goal of both perspectives as a result of CF. Thus, CF should be considered through the double lens that results from the marriage of these perspectives; one perspective should not be emphasized at the cost of the other. Teachers should orchestrate their CF in a way that satisfies students' cognitive and social needs at the same time. For example, teachers are encouraged to focus on meaning while they gradually provide the correction to their students on forms and vice versa. In other words, teachers should not focus primarily on linguistic input while ignoring socially mediating factors, such as students' motivation to take part in the correction [3].

Why do we not deal with students' errors in a way that is socially cognitive and cognitively social? This paper should provide a bridging understanding between social and cognitive interactionist perspectives by emphasizing the utility of CF as an important aspect of teaching/learning processes. It should also open avenues for future investigations through the doubled lens from which CF can be viewed.

\subsection{Practice Implication}

In light of the marriage of the two perspectives and due to the fact that there has never been a 'one size fits all' solution to CF practices, the following recommendations should serve as a starting set for CF practices in EFL tertiary contexts:

- CF should be provided in a way that challenges students' abilities to move them to the upper levels of accuracy and fluency;

- CF should enhance students' awareness of the corrective function of the strategy used;

- CF should direct students' attention to what is missing in their language proficiency reservoir;

- CF should provide students to compare their errors with the correct forms;

- CF should be context-dependent as students' needs are different;

- CF should be fine-tuned to cope with students' different levels of proficiencies and characters;

- CF should not be exaggerated or overused, as not all errors need to be dealt with;

- CF should not be provided by teachers alone, as students can take part in correction as well; and

- CF should not be oversimplified in a way that limits students' awareness capacity of language accuracy and fluency.

\section{The Way Ahead}

Both perspectives should consider long term acquisition as an aim of their investigation rather than postulating incorporation of correction in subsequent productions. Cognitive interactionists measure learning by the students' uptake, while social interactionists measure learning by reducing other-regulation. Both perspectives should consider learning as correct usage of TL within the new context of language production, not just within the context of correction. More empirical evidence is direly needed.

Future efforts may consider blending both perspectives when investigating CF. Specifically, researchers are encouraged to measure EFL students' subsequent incorporation of $\mathrm{CF}$ in light of the their noticing, their level of proficiency, and their ability and readiness to deal with correction within the social context.

\section{Acknowledgement}

This paper has been presented in the AILA World Congress Conference 2014 in Brisbane, Australia. It was in the form of poster. Following the feedback and comments received from the audience and the specialists in the field who attended the conference, the presentation has been greatly modified and become a paper.

\section{Statement of Competing Interest}

This author has no competing interests. 


\section{List of Abbreviations}

\author{
CF- Corrective Feedback \\ EFL- English as a Foreign Language \\ ESL- English as a Second Language \\ L1- First language \\ SLA- Second Language Acquisition \\ ZPD- Zone of Proximal Development.
}

\section{References}

[1] Aljaafreh, A., \& Lantolf, J. P., Negative feedback as regulation and second language learning in the zone of proximal development. The Modern Language Journal, 78(4), 465-483 (1994).

[2] Althobaiti, N., EFL teachers' beliefs, instructional practices and professional development about corrective feedback in Saudi universities. (Doctoral dissertation). University of Queensland, Brisbane (2013).

[3] Bitchener, J. \& Storch, N., Written corrective feedback for SLA Theoretical perspectives and empirical research. UK: Multilingual Matters (2013).

[4] Corder, S. P., The significance of learners' errors. International Review of Applied Linguistics, 5, 161-169 (1967).

[5] Darhower, M., Interactional features of synchronous computermediated communication in the intermediate L2 class: A sociocultural case study. CALICO Journal, 19(2), 249-277 (2002).

[6] Donato, R., Sociocultural contributions to understanding the foreign and second language classroom. In J. P. Lantolf (Ed.), Sociocultural theory and second language learning (pp. 27-52). NY: Oxford University Press (2000).

[7] Donato, R., A sociocultural perspective on language learning strategies: The role of mediation. The Modern Language Journal, 78(4), 453-464 (1994).

[8] Egi, T., Verbal reports, noticing, and SLA research. Language Awareness 13, 243-264 (2004).

[9] Ellis, R., Epilogue: A framework for investigating oral and written corrective feedback. Studies in Second Language Acquisition, 32(2), 335-349 (2010).

[10] Firth, A., \& Wagner, J., On discourse, communication, and (some) fundamental concepts in SLA research. The Modern Language Journal, 81(3), 285-300 (1997).

[11] Gass, S. M. \& Selinker, L., Second Language Acquisition: An Introductory Course. London: Lawrence Earlbaum (2001).

[12] Gass, S., Input and interaction. In C. Doughty \& M. Long (Eds.), The handbook of second language acquisition (pp. 224-255). Oxford: Blackwell (2003).

[13] Gass, S., Input, interaction and the second language learner. Mahway, NJ: Lawrence Erlbaum (1997).

[14] Gitsaki, C., \& Althobaiti, N., ESL teachers' use of corrective feedback and its effect on learners' uptake. Asia TEFL, 7(1), 197219 (2010).

[15] Hatch, E., Discourse analysis and second language acquisition. In E. Hatch (Ed.), Second language acquisition. Rowley, Mass.: Newbury House (1978).

[16] Hermans-Nymark, L. D., English in the EFL classrooms: Why not? (Doctoral dissertation). Nijmegen: Radboud University. (2007).

[17] Izumi, S., Output, input enhancement, and the noticing hypothesis.

[18] Krashen, S., Principles and practice in second language acquisition. London: Pergamon Press (1982)
[19] Lantolf, J. P., \& Thorne, S. L., Sociocultural theory and second language learning. In B. VanPatten \& J. Williams (Eds.), Theories in second language acquisition (pp. 201-224). Mahwah, NJ: Lawrence Erlbaum Associates (2007).

[20] Lantolf, J. P., Socio-cultural theory and second language learning. Oxford: Oxford University Press (2000).

[21] Long, M., Problems in SLA. Mahwah, NJ: Lawrence Erlbaum (2007).

[22] Long, M. H. Focus on form: A design feature in language teaching methodology. In K. de Bot, R. Ginsberg, \& C. Kramsch (Eds.), Foreign language research in cross-cultural perspective (pp. 3952). Philadelphia: Benjamins (1991).

[23] Long, M. H., The role of the linguistic environment in second language acquisition. In W. C. Ritchie \& T. K. Bhatia (Eds.), Handbook of second language acquisition (Vol. 2: Second language acquisition, pp. 413-468). New York: Academic (1996).

[24] Long, M., \& Robinson, P., Focus on form: Theory, research and practice. In C. Doughty \& J. Williams (Eds.), Focus on form in classroom second language acquisition (pp. 15-41). Cambridge: Cambridge University Press (1998).

[25] Lyster, R., \& Mori, H., Interactional feedback and instructional counterbalance. Studies in Second Language Acquisition, 28(2), 269-300 (2006).

[26] Mitchell R., \& Myles, F., Second Language Learning Theories ( $2^{\text {nd }}$ ed.). Great Britain: Hodder Arnold (2004).

[27] Nabei, T., Recasts in classroom interaction: A teacher's intention, learners' attention, and second language learning. (Doctoral dissertation). University of Toronto, Canada (2002).

[28] Nassaji, H., \& Fotos, S., Teaching grammar in second language classrooms: Integrating form-focused instruction in communicative context. New York: Routledge (2011).

[29] Nassaji, H., \& Swain, M., A Vygotskian perspective on corrective feedback in L2: The effect of random versus negotiated help on the learning of English articles. Language Awareness, 9(1), 34-51 (2000).

[30] Ortega, L., Meaningful L2 practice in foreign language classrooms: A cognitive-interactionist SLA perspective. In: Practice in a Second Language. pp. 180-207. [Online]. Cambridge Applied Linguistics. Cambridge: Cambridge University Press (2007).

[31] Russell, V., Corrective feedback, over a decade of research since Lyster and Ranta (1997): Where do we stand today? Electronic Journal of Foreign Language Teaching 6(1), 21-31 (2009).

[32] Schmidt, R., Attention. In P. Robinson (Ed.), Cognition and second language instruction (pp. 3-32). Cambridge, UK: Cambridge University Press (2001).

[33] Schmidt, R., The role consciousness in second language learning. Applied Linguistics, 1, 129-158 (1990).

[34] Selinker, L., Interlanguage. International Review of Applied Linguistics, 10, 209-31 (1972).

[35] Sheen, Y., Corrective feedback, individual differences and second language learning. Dordrecht, The Netherlands: Springer (2012).

[36] Sheen, Y., Corrective feedback and learner uptake in communicative classrooms across instructional settings. Language Teaching Research, 8(3), 263-300 (2004).

[37] Swain, M., Communicative competence: Some roles of comprehensible input and comprehensible output in its development. In S. Gass \& C. Madden (Eds.), Input in second language acquisition (pp. 235-253). Rowley, MA: Newbury House (1985).

[38] Swain, M., Examining dialogue: Another approach to content specification and to validating inferences drawn from test scores. Language Testing, 18(3), 275-302 (2001).

[39] Vygotsky, L. S. Thinking and speech. In R. W. Rieber \& A. S. Carton (Eds.), The collected works of L. S. Vygotsky (Vol. 1, pp. 37-285). New York: Plenum Press (1987). 